\title{
all-trans-Retinoic acid preserves viability of fibroblasts and keratinocytes in full-thickness, human skin and fibroblasts in isolated dermis in organ culture
}

\author{
James Varani ${ }^{1}$, Patricia Perone ${ }^{1}$, Suzanne E. G. Fligiel ${ }^{3}$, Dennis R. Inman ${ }^{3}$, John J. Voorhees ${ }^{2}$ \\ ${ }^{1}$ Department of Pathology, The Universtiy of Michigan Medical School, 1301 Catherine Road, Box 0602, Ann Arbor, MI 48109, USA \\ Tel. (313) 764-9287; Fax (313) 763-6476 \\ ${ }^{2}$ Department of Dermatology, The University of Michigan Medical School, Ann Arbor, MI 48109, USA \\ ${ }^{3}$ Department of Pathology, VAMC - Wayne State University, Allen Park, MI 48102, USA
}

Received: 15 October 1993

\begin{abstract}
Human dermal fibroblast and human epidermal keratinocyte survival was examined under various conditions in organ culture. Using cell recovery from organ-cultured tissue as the criterion, it was observed that no keratinocytes and few fibroblasts survived incubation for 10-12 days in serum-free basal medium containing a low level $(0.15 \mathrm{~m} M)$ of extracellular $\mathrm{Ca}^{2+}$. Increasing the extracellular $\mathrm{Ca}^{2+}$ concentration to $1.4 \mathrm{mM}$ or treating the tissue with $3 \mu M$ retinoic acid (RA) under low $\mathrm{Ca}^{2+}$ conditions resulted in increased keratinocyte and fibroblast survival; the two treatments together were more effective than either treatment alone. The same treatments preserved fibroblast survival when pieces of isolated dermal tissue were incubated in organ culture and also supported fibroblast survival in monolayer culture. These findings indicate that recovery of keratinocytes and fibroblasts from skin after maintenance in organ culture provides a simple but definitive measure of the viability of the major cellular elements present in the tissue. These findings suggest that RA treatment enhances survival of both fibroblasts and keratinocytes and that these effects of RA can be seen at physiological $\mathrm{Ca}^{2+}$ concentrations as well as at suboptimal levels of extracellular $\mathrm{Ca}^{2+}$. Finally, these results indicate that the dermis is a direct target of RA.
\end{abstract}

Key words: Skin organ culture - Retinoic acid - Cell viability

\section{Introduction}

Topical application of all-trans-retinoic acid (RA) alters the histological appearance of skin, and this is associated with changes in both the epidermis and dermis [15-17,

Correspondence to: J. Varani
36]. A major feature of the epidermis is an overall thickening, due in part to increased keratinocyte proliferation and in part to increased synthesis of glycosaminoglycans $[17,36]$. In the dermis there is evidence of fibroblast activation and new matrix synthesis $[12,15,16]$. We have recently demonstrated similar findings using an organ culture model $[33,34]$. Both the topical treatment data (in vivo studies) and our own data in the organ culture model suggest that RA influences the behavior of each of the two major cellular elements of skin. However, this is difficult to "prove" on the basis of histology alone. The present study was carried out, therefore, to demonstrate that RA does indeed preserve the viability of both epidermal keratinocytes and dermal fibroblasts in organ-cultured human skin.

Materials and methods

Retinoic acid

RA was obtained from the R.W. Johnson Pharmaceutical Research Institute (Raritan, N.J.) and prepared as a $20 \mathrm{mg} / \mathrm{ml}$ solution in dimethyl sulfoxide (DMSO). The stock solution was stored at $-20^{\circ}$ $\mathrm{C}$ in the dark until use. At the time of use, it was diluted directly in Keratinocyte Basal Medium (KBM) (Clonetics, San Diego, Calif.) and added to the cultures. In the cultures treated with $3 \mu M$ RA (highest concentration tested), the final concentration of DMSO in the culture medium was $0.005 \%$. This amount of DMSO had no detectable effect by itself.

\section{Organ cultures}

Organ cultures were established from healthy adult volunteers. Briefly, $2 \times 2 \mathrm{~mm}$ full-thickness punch biopsies were obtained from the hips (normally eight biopsies per person) and immediately placed into the wells of a 24-well dish containing $0.5 \mathrm{ml}$ $\mathrm{KBM} . \mathrm{KBM}$ is a serum-free basal medium consisting of modified MCDB-153 medium. The $\mathrm{Ca}^{2+}$ concentration of the KBM was $0.15 \mathrm{~m} M$. We routinely included duplicate biopsies per well. One group was left without further treatment while RA $(3 \mu M)$ was added to the KBM in other wells. In additional wells, calcium 
chloride was added to bring the final $\mathrm{Ca}^{2+}$ concentration to 1.4 $\mathrm{m} M$, and $3 \mu M \mathrm{RA}$ was included in some of these wells. The organ cultures were then incubated at $37^{\circ} \mathrm{C}$ in an atmosphere containing $5 \% \mathrm{CO}_{2}$ in the dark with fresh culture medium and treatments provided at 2 -day intervals.

Additional biopsies were obtained in the normal manner and then immediately placed in a solution of $0.25 \%$ trypsin $/ 0.05 \%$ EDTA. After $1 \mathrm{~h}$ of incubation, the dermis and epidermis were gently separated using forceps. The trypsin was neutralized by incubation for an additional $15 \mathrm{~min}$ in a solution of soybean trypsin inhibitor $(100 \mu \mathrm{g} / \mathrm{ml})$ in $\mathrm{KBM}$. After two washes in $\mathrm{KBM}$, the isolated dermal tissue pieces were incubated in KBM, treated with $\mathrm{Ca}^{2+}$ and/or RA and incubated for up to 12 days as described above. No attempt was made to incubate the isolated epidermal tissue pieces since histological studies indicated that they underwent rapid and complete necrosis when kept in organ culture after separation from the dermis.

\section{Isolation of keratinocytes and fibroblasts from organ-cultured tissue}

At the end of the incubation period, tissue specimens that had been incubated in either KBM alone or in KBM supplemented with extracellular $\mathrm{Ca}^{2+}$ and/or RA were harvested, minced using scissors and forceps and plated on tissue culture plastic in Minimal Essential Medium of Eagle with Earle's salts, non-essential amino acids and $10 \%$ fetal bovine serum (MEM-FBS). Since the total amount of tissue available from each biopsy was so small, the duplicate pieces from each well were chopped, minced and incubated together. Cultures were provided fresh medium as needed and examined daily for fibroblast and keratinocyte outgrowth. The same MEM-FBS was used for cell outgrowth from all tissues so as not to bias the chances of recovering cells from different tissues. Further, this medium has proven satisfactory in the past for isolation of both fibroblasts and keratinocytes $[19,31]$. After 20 days, all tissue specimens were discarded if no keratinocytes or fibroblasts were recovered. If keratinocytes and/or fibroblasts were recovered. They were harvested with trypsin and subcultured. By first passage, fibroblasts made up virtually $100 \%$ of the remaining cells. These cells were then used to assess growth in monolayer culture. The failure to maintain keratinocytes beyond primary culture probably reflected the fact that these cells undergo differentiation in serum-containing medium and that differentiated cells fail to reattach to the substratum after exposure to proteases [19, 29].

\section{Fibroblast growth in monolayer cluture.}

Fibroblasts were harvested from culture at passage $1-3$ and plated at $5 \times 10^{4}$ cells per well in 24-well culture dishes. MEM-FBS was used as culture medium. After the cells had had a chance to attach, duplicate wells were harvested and counted to obtain zero-time counts. The remaining cells were washed twice in KBM and treated for 2 days in KBM alone $\left(0.15 \mathrm{mMC \textrm {Ca } ^ { 2 + }}\right)$ or in KBM supplemented with extracellular $\mathrm{Ca}^{2+}(1.4 \mathrm{~m} M$, final concentration) and/or RA $(3 \mu M)$. At the end of the incubation period, cells were harvested and counted. An electronic particle counter was used to assess cell numbers after first verifying that the cells were in single-cell suspension.

\section{Results}

Recovery of fibroblasts from whole-skin organ culture and from isolated dermis

In the first series of experiments, fibroblast viability was assessed after incubation in organ culture. The results of these experiments are shown in Table 1. Fibroblasts were
Table 1. Fibroblast isolation after incubation in organ culture

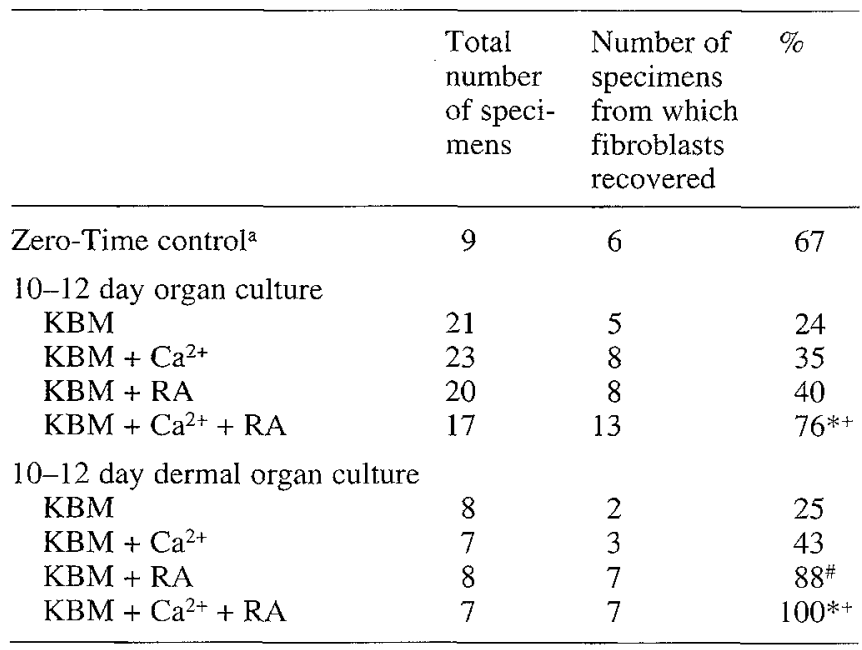

a Fibroblasts isolated immediately after biopsy (i.e. no time in organ culture)

$* P<0.05, \mathrm{Ca}^{2+}+\mathrm{RA}$ vs KBM alone ${ }^{+} P<0.05, \mathrm{Ca}^{2+}+\mathrm{RA}$ vs $\mathrm{Ca}^{2+}$ alone; ${ }^{*} P<0.05$, RA vs KBM alone; significance of differences determined by the Scheffe method [37]

Table 2. Keratinocyte isolation after incubation in organ culture

\begin{tabular}{llll}
\hline & $\begin{array}{l}\text { Total } \\
\text { number } \\
\text { of speci- } \\
\text { mens }\end{array}$ & $\begin{array}{l}\text { Number of } \\
\text { specimens } \\
\text { from which } \\
\text { keratinocytes } \\
\text { recovered }\end{array}$ \\
\hline $\begin{array}{lll}\text { Zero-Time control } \\
\text { ra }\end{array}$ & 9 & 6 & 78 \\
10-12 day organ culture & 13 & 0 & 0 \\
$\mathrm{KBM}$ & 13 & 8 & $62^{!}$ \\
$\mathrm{KBM}+\mathrm{Ca}^{2+}$ & 12 & 4 & $33^{*}$ \\
$\mathrm{KBM}+\mathrm{RA}^{\mathrm{KBM}}+\mathrm{Ca}^{2+}+\mathrm{RA}$ & 11 & 10 & $91^{*+}$ \\
\hline
\end{tabular}

a Keratinocytes isolated immediately after biopsy (i.e. no time in organ culture)

$! P<0.05, \mathrm{Ca}^{2+}$ vs KBM alone, $P<0.05, \mathrm{RA}$ vs KBM alone; $* P<0.05, \mathrm{Ca}^{2+}+\mathrm{RA}$ vs KBM alone; ${ }^{+} P<0.05, \mathrm{Ca}^{2+}+\mathrm{RA}$ vs $\mathrm{Ca}^{2+}$ alone; significance of differences determined by the Scheffe method [37]

recovered from only 5 of 21 specimens (24\%) after incubation of the tissue for 12 days in (low- $\mathrm{Ca}^{2+}$ ) KBM alone. This compares with 8 of 23 (35\%) from the group incubated in KBM supplemented with $1.4 \mathrm{~m} M \mathrm{Ca}^{2+}, 8$ of 20 $(40 \%)$ from the group incubated in KBM supplemented with $3 \mu M$ RA and 13 of 17 (76\%) from the group incubated in KBM supplemented with both $1.4 \mathrm{mM} \mathrm{Ca}{ }^{2+}$ and $3 \mu M$ RA. By comparison, fibroblasts were recovered from 6 of 9 control tissue pieces of the same size $(67 \%)$ established immediately after biopsy.

In a second experiment, isolated dermal tissue was obtained from eight additional volunteers and incubated for 12 days in KBM alone or in KBM supplemented with 1.4 $\mathrm{m} M \mathrm{Ca}^{2+}$ and/or $3 \mu M$ RA. Following incubation in organ culture, fibroblast recovery was assessed as with intact tissue. It can be seen that, just as with intact tissue, fibroblast recovery was higher in the presence of RA than 
in its absence (Table 1). The percentage of RA-treated cultures from which fibroblasts were recovered was higher when isolated dermis was used in place of intact tissue (7. of 7 and 7 of 8 vs 8 of 20 and 13 of 17).

\section{Recovery of keratinocytes from organ-cultured tissue}

Table 2 presents the results of efforts to isolate keratinocytes from the same organ-cultured tissue pieces. In the absence of organ culture supplementation with either $\mathrm{Ca}^{2+}$ or RA, there was no keratinocyte recovery (zero isolates from a total of 13 different tissue). In contrast, supplementation of the organ-cultured tissue with either $\mathrm{Ca}^{2+}$ or RA improved keratinocyte recovery rates $\left(\mathrm{Ca}^{2+}\right.$ being the more effective of the two) and supplementation with both $\mathrm{Ca}^{2+}$ and RA resulted in the highest recovery (10 of $11 ; 91 \%)$. By comparison, keratinocytes were recovered from 7 of 9 control specimens (78\%) established immediately after biopsy.

\section{Survival of fibroblasts in monolayer culture after isolation from organ-cultured tissue}

Fibroblasts recovered from organ-cultured skin (28 separate isolates) were examined for their ability to survive for 2 days in monolayer culture under the same four conditions used with organ culture. When the data from all of 28 isolates were analyzed together, only $36 \%$ of the cells plated on day 0 were recovered after incubation for 2 days in KBM alone (Table 3). Supplementation of KBM with either $1.4 \mathrm{mM} \mathrm{Ca}{ }^{2+}$ or $3 \mu M$ RA resulted in significantly increased cell recovery (Table 3 ). Combined treatment with $1.4 \mathrm{mMCa} \mathrm{Ca}^{2+}$ and RA preserved a greater percentage of the cells than either $1.4 \mathrm{~m} M \mathrm{Ca}^{2+}$ or $3 \mu M \mathrm{RA}$ alone (Table 3).

Although supplementation with extracellular $\mathrm{Ca}^{2+}$ or treatment with RA appeared to act in concert when data from all 28 of the adult fibroblast isolates were examined together (Table 3), these data do not indicate the degree of heterogeneity among the isolates. For example, 22 or the 28 isolates responded to supplementation with $1.4 \mathrm{mM}$

Table 3. Fibroblast survival and growth under serum-free conditions; effects of $\mathrm{Ca}^{2+}$ and/or RA

\begin{tabular}{lll}
\hline $\begin{array}{l}\text { Fibroblast } \\
\text { treatment }\end{array}$ & $\begin{array}{l}\text { 48-h cell } \\
\text { counts } \\
(\text { no. of } \\
\left.\text { cells } \times 10^{4}\right)\end{array}$ & $\begin{array}{l}\text { Proportion of } \\
\text { responsive } \\
\text { isolates }\end{array}$ \\
\hline $\mathrm{KBM}$ & $1.8 \pm 0.6$ & - \\
$\mathrm{KBM}+\mathrm{Ca}^{2+}$ & $2.8 \pm 1.2^{*}$ & $22 / 28$ \\
$\mathrm{KBM}+\mathrm{RA}^{\mathrm{c}}$ & $2.4 \pm 0.9^{*}$ & $15 / 28$ \\
$\mathrm{KBM}+\mathrm{Ca}^{2+}+\mathrm{RA}$ & $3.2 \pm 1.4^{* *}$ & $28 / 28$ \\
\hline
\end{tabular}

a Treatment under which the fibroblast isolates were incubated for 2 days in monolayer culture

${ }^{b}$ Number of cells per well in the culture dish after incubation. Values shown are means \pm standard deviations

c Number of isolates (out of a total of 28) that responded better to supplementation with $1.4 \mathrm{~m} M \mathrm{Ca}^{2+}, \mathrm{RA}$ or the combination of $\mathrm{Ca}^{2+}$ and RA than to low- $\mathrm{Ca}^{2+} \mathrm{KBM}$ alone

$* P<0.05 ; * * P<0.01$ vs KBM alone; significance of differences determined by ANOVA
$\mathrm{Ca}^{2+}$ (i.e. a significantly higher percentage of cells survived in this medium than in KBM alone), 15 of the 28 isolates responded to treatment with $3 \mu M \mathrm{RA}$ in low $-\mathrm{Ca}^{2+}$ culture medium and 28 of the 28 isolates responded to the combination of $\mathrm{Ca}^{2+}$ supplementation and RA treatment (Table 3). Finally, when we compared the responses of the isolates to $\mathrm{Ca}^{2+}$ alone and to the combination of $\mathrm{Ca}^{2+}$ and RA, we found that 17 of the 28 isolates responded better to the combined treatment. Interestingly, however, only one of these 17 isolates was from a tissue that had been maintained in organ culture in KBM supplemented with $\mathrm{Ca}^{2+}$ alone $(1 / 7,14 \%)$. The other 16 isolates were from tissues that had been maintained in organ culture in KBM alone, in KBM treated with RA or in KBM treated with $\mathrm{Ca}^{2+}$ and $\mathrm{RA}(16 / 21,76 \%)(P<0.01$ by Chi-squared test $)$.

\section{Discussion}

Topical treatment of human skin with RA induces a number of histological changes that can be seen in both the epidermis and the dermis $[15-17,36]$. The cellular and molecular events underlying the histological alterations have not been fully elucidated, and this is due, in part at least, to the difficulty in carrying out the types of interventional studies in humans that would elucidate mechanisms of action. To obviate this problem, we have recently utilized an organ culture model of human skin to evaluate the effects of RA. Using this model we found that RA preserves the histological architecture of both the epidermis and the dermis over a 12-day period in serum-free, growth factor-free basal medium under conditions of both low and high extracellular $\mathrm{Ca}^{2+}[33]$. A variety of other factors that are known to support fibroblast and/or keratinocyte proliferation in monolayer culture $[7,8,10,11,18,20$, 23] were incapable of duplicating this effect $[33,34]$. The similarity between the histological features seen in RAtreated skin in organ culture and those observed in vivo suggest that the organ culture model provides a good approximation of intact skin and will be a useful tool for elucidating mechanisms of RA action that are applicable to in vivo use.

How retinoids work at the cellular level is not fully understood. The present study demonstrated that RA treatment of organ-cultured human skin preserved viability for both the fibroblast and the epithelial cell populations. Using cell recovery from tissue pieces after incubation in organ culture as the criterion, our data showed that there was enhanced recovery of both cellular components from RA-treated skin as compared with matched controls from the same volunteers. The previously noted improvement in histological features of organ-cultured skin following treatment with RA $[33,34]$ was thus correlated with preservation of cell viability in both the epidermis and the dermis. Past studies have suggested that retinoids act by reversing specific events associated with excess exposure to sunlight. These include stimulating collagen production $[1,12,28]$ and inhibiting enzymes involved in collagen degradation $[2,6,30]$. While the present data do not contradict previous results, they suggest that RA also, has more basic effects as, i.e. preserving cell viability. 
Although RA has growth-promoting activity for both keratinocytes and fibroblasts in monolayer culture [30, 31 ], it is unclear from in vivo studies as to whether the direct target of retinoid action in skin is the epidermis, the dermis or both. Induction of epithelial glands in rodent skin by retinoids is thought to results from a retinoid effect on the mesenchymal components $[9,13,22,35]$. In contrast, results from human skin-equivalent cultures suggest that keratinocytes are the target cells and the fibroblasts act in some manner to downregulate keratinocyte responses [27]. Although the present studies do not rule out the epidermis as a direct target, our results show that the dermis clearly is. In the presence of RA, fibroblast viability in both whole-skin organ culture and isolated dermis was preserved. Indeed, RA was more effective at maintaining fibroblast viability in the isolated dermis than in the intact tissue. This may reflect epidermal metabolism of RA with a resultant decrease in the effective concentration of the retinoid reaching the dermis.

Whether the epidermis is also a direct target of RA could not be assessed as the epidermal tissue quickly degenerated after separation from the dermis. Since RA is known to promote keratinocyte growth in monolayer culture [30], it would not be unreasonable to suggest that the ability of RA to preserve epidermal structure in organ culture is a reflection of this. This may not be the case, however, since a number of different factors that stimulate keratinocyte proliferation in monolayer $[7,8,10,11,18$, $20,23]$ are completely unable to preserve epidermal structure in organ culture [33, 34]. Furthermore, keratinocytes proliferate actively in monolayer culture at low extracellular $\mathrm{Ca}^{2+}(0.05-0.15 \mathrm{mM})$ levels. Raising the $\mathrm{Ca}^{2+}$ concentration to $1.4 \mathrm{~m} M$ slows growth and induces differentiation $[3,14,19,21]$. The opposite is true in organ culture. Thus, observations made with isolated keratinocytes in monolayer culture are of limited value, at best, in understanding how epidermal structure is maintained in organ culture. In contrast, the histological structure of the epidermis $[33,34]$ and keratinocyte recovery from organ-cultured tissue (this report) are both dramatically improved under two conditions (i.e. high-Ca ${ }^{2+} \mathrm{KBM}$ or low- $\mathrm{Ca}^{2+}$ KBM supplemented with RA) that clearly act in a positive fashion on the dermal fibroblasts $[4,5,31,32]$. Our interpretation of these data is that, regardless of whether or not RA acts on the epidermis directly, maintenance of structure and function in the epidermis in RA-treated organcultured skin is primarily a reflection of a direct retinoid effect on the dermis.

Although the data presented here clearly show that fibroblasts are a target of retinoid action in both organ culture and monolayer culture, how RA acts to preserve the viability of these cells under conditions in which they would otherwise die is not fully understood. Enhanced fibroblast viability was observed in high-Ca ${ }^{2+}$ culture medium as well as low-Ca ${ }^{2+}$ culture medium. Previous studies with neonatal (foreskin) fibroblasts showed similar effects with RA under low-Ca ${ }^{2+}$ conditions, but in high- $\mathrm{Ca}^{2+}$ culture medium, neonatal fibroblasts survived without RA and the addition of RA produced no benefit [32]. It seems reasonable to suggest that RA functions in some manner to overcome the limitation imposed by insufficient $\mathrm{Ca}^{2+}$ on fibroblast function. While it is difficult to extrapolate from monolayer and organ culture data to what might occur in intact skin, one could postulate that a progressive decrease in responsiveness to extracellular $\mathrm{Ca}^{2+}$ in dermal fibroblasts as a function of aging (noted in previous studies by others $[4,5,24-26]$ ) provides a target of opportunity for retinoid action.

Acknowledgements. This study was supported by a grant from the R. W. Johnson Pharmaceutical Research Institute. The authors acknowledge the help of Mr. Ted A. Hamilton with the statistical analysis of the data.

\section{References}

1. Angeles AM, Kahari V-M, Chen YQ, Ramirez F, Uitto J (1990) Enhanced collagen gene expression in fibroblast cultures treated with all-trans retinoic acid: Evidence for up-regulation of the $\alpha 2(1)$ promoter activity (abstract). J Invest Dermatol 94 : $504 \mathrm{~A}$

2. Bauer EA, Seltzer JL, Elsen AZ (1982) Inhibition of collagen degradive enzymes by retinoic acid in vitro. J Am Acad Dermatol $6: 603-607$

3. Boyce ST, Ham RG (1983) Calcium regulated differentiation of normal human epidermal keratinocytes in chemically-defined clonal culture and serum-free serial culture. J Invest Dermatol $81: 33-40$

4. Boynton AL, Whitfield JF, Isaacs RJ, Morton HJ (1974) Control of 3 T3 cell proliferation by calcium. In Vitro $10: 12-17$

5. Boynton AL, Whitfield JF, Isaacs RJ, Tremblay R (1977) The control of human WI-38 proliferation by extracellular calcium and its elimination by SV-40 virus-induced proliferative transformation. J Cell Physiol 92 : 241-248

6. Clark SD, Kobayashi DK, Welgies HG (1987) Regulation of the expression of tissue inhibitor of metalloproteinases and collagenases by retinoids and glucocorticoids in human fibroblasts. J Clin Invest 80: 1280-1288

7. Colige A, Nusgens B, Lapiere CM (1990) Response to epidermal growth factor of skin fibroblasts from donors of varying age is modulated by the extracellular matrix. J Cell Physiol $145: 450-457$

8. Cook PW, Pittelkow MR, Shipley GD (1991) Growth factorindependent proliferation of normal human neonatal keratinocytes: Production of autocrine and paracrine-acting mitogenic factors. J Cell Physiol $146: 277-289$

9. Covant HA, Hardy MH (1990) Excess retinoid acts through the stroma to produce mucous glands from newborn hamster cheek pouch in vitro. J Exp Zool $253: 271-279$

10. Elder J, Fisher G, Lindquist P, Bennett G, Pittlekow P, Coffey E, Ellingsworth L, Derynck R, Voorhees J (1989) Over expression of transforming growth factor- $\alpha$ in psoriatic epidermis. Science $243: 811-814$

11. Flier JS, Usher P, Moses AC (1986) Monoclonal antibody to the type I insulin-like growth factor (IGF-I) receptor blocks IGF-I receptor-mediated DNA synthesis: clarification of the mitogenic mechanisms of IGF-I and insulin in human skin fibroblasts. Proc Natl Acad Sci USA 83: 664-668

12. Griffiths CEM, Russman A, Majmudar G, Singer RS, Hamilton TA, Voorhess JJ (1993) Restoration of collagen formation in photodamaged human skin by tretinoin (retinoic acid). N Engl J Med $329:$ 530-535

13. Hardy M, Dhouailly D, Torma H, Vahlquist A (1990) Either chick embryo dermis or retinol-treated mouse dermis can initiate glandular morphogenesis from mammalian epidermal tissue. J Exp Zool $256: 279-289$

14. Hennings H, Michael D, Cheng C, Steinert P, Holbrook K, Yuspa SH (1980) Calcium regulation of growth and differentiation of mouse epidermal cells in culture. Cell $9: 245-254$ 
15. Kligman LH (1986) Effects of all-trans retinoic acid on the dermis of hairless mice. I Am Acad Dermatol 5 : 779-785

16. Kligman LH, Duo CH, Kligman AM (1984) Topical retionic acid enhances the repair of ultraviolet damaged dermal connective tissue. Connect Tissue Res 12:139-150

17. Kligman AM, Grove GL, Hirose R (1986) Topical tretinoin for photoaged skin. J Am Acad Dermatol 15:836-859

18. Krane JF, Murphy DP, Carter DM, Kruger JG (1991) Synergistic effects of epidermal growth factor (EGF) and insulin-like growth factor I/Somatomedian C (IFG-I) on keratinocyte proliferation may be mediated by IGF-I transmodulation of the EGF receptor. J Invest Dermatol $96: 419-424$

19. Liu S, Karasek M (1978) Isolation and growth of adult human epidermal keratinocytes in cell culture. J Invest Dermatol 71 : $157-162$

20. Maciag T, Nemore RE, Weinstein R (1981) An autocrine approach to the control of epidermal growth: serum-free cultivation of human keratinocytes. Science $211: 1452-1454$

21. Milstone LM (1987) Calcium modulates growth of human keratinocytes in confluent cultures. Epithelia $1: 129-140$

22. Obinata A, Kawada M, Endo H (1987) Induction of epidermal mucous metaplasia by culture of recombinants of undifferentiated epidermis and retinol-treated dermis in a chemically defined medium. Dev Biol 123 : 59-62

23. O'Keefe EJ, Chiu ML (1988) Stimulation of thymidine incorporation in keratinocytes by insulin, epidermal growth factor and placental extract: comparison with cell number to assess growth. J Invest Dermatol $90: 2-7$

24. Praeger FC, Cristofalo VJ (1980) Effects of elevated levels of extracellular $\mathrm{Ca}^{++}$on young and old WI-38 cells. In Vitro 16 : 239-245

25. Praeger FC, Cristofalo VJ (1984) Age-related loss of response to elevated $\left[\mathrm{CaCl}_{2}\right]$ by WI-38 cells. Gerontologist $24: 226-227$

26. Praeger FC, Cristofalo VJ (1986) Modulation of WI-38 cell proliferation by elevated levels of $\mathrm{CaCl}_{2}$. J Cell Physiol 129 : $27-35$

27. Sanquer S, Coulomb B, Lebreton C, Debertret L (1990) Human dermal fibroblasts modulate the effects of retinoids on epidermal growth. J Invest Dermatol 95 : 700-704
28. Schwartz E, Cruikshank FA, Mezick JA, Kligman LH (1991) Topical all-trans retinoic acid stimulates collagen synthesis in vivo. J Invest Dermatol $96: 976-978$

29. Varani J, Nickoloff BJ, Riser BL, Mitra RS, O'Rouke K, Dixit VM (1988) Thrombospondin-induced adhesion of human keratinocytes. J Clin Invest $81:$ 1537-1544

30. Varani J, Nickoloff BJ, Mitra RS, Dixit VM, Voorhees JJ (1989) All-trans retinoic acid stimulates growth of adult human keratinocytes cultured in growth factor-deficient medium, inhibits production of thrombospondin and fibronectin and reduces adhesion. J Invest Dermatol $93: 449-454$

31. Varani J, Mitra RS, Gibbs D, Phan SH, Dixit VM, Wang T, Nickoloff BJ, Voorhees JJ (1990) All-trans retinoic acid stimulates growth and extracellular matrix production in growthinhibited cultured human skin fibroblasts. J Invest Dermatol $94: 717-723$

32. Varani J, Shayevitz J, Perry D, Mitra RS, Nickoloff BJ, Voorhess JJ (1990) Retinoic acid stimulation of human dermal fibroblast proliferation is dependent on suboptimal extracellular $\mathrm{Ca}^{2+}$ concentration. Am J Pathol 136: 1275-1281

33. Varani J, Fligiel SEG, Schuger L, Perone P, Inman DR, Griffiths CEM, Voorhees JJ (1993) Effects of all-trans retinoic acid and $\mathrm{Ca}^{++}$on human skin in organ culture. Am J Pathol 142 : $189-198$

34. Varani J, Fligiel SEG, Perone P, Inman DR, Voorhees JJ (1993) Effects of sodium lauryl sulfate on human skin in organ culture: comparison with all-trans retinoic acid and epidermal growth factor. Dermatology $187: 19-25$

35. Viallet JP, Ruberte E, Du Manoir S, Krust A, Zelent A, Dhouailly D (1991) Retinoic acid-induced glandular metaplasia in mouse skin is linked to the dermal expression of retinoic acid receptor $\beta$ mRNA. Dev Biol 114: 424-428

36. Weiss JS, Ellis CN, Headington JT, Tincoff T, Hamilton TA, Voorhees JJ (1988) Topical tretinoin improves photoaged skin. JAMA $259: 527-532$

37. Woolson RF (1987) Statistical methods for the analysis of biomedical data. Wiley, New York, p 390 